\title{
NUMERICAL ANALYSIS OF GEOTHERMAL TUNNELS
}

\author{
Aparna Kanth ${ }^{1}$, Tanusree Chakraborty ${ }^{2}$ \\ ${ }^{l}$ Asst. Professor, Civil Engg. Dept., S.I.E.T, Greater Noida, U.P, India-201308 \\ ${ }^{2}$ Asst. Professor, Civil Engg. Dept., IIT Delhi, India-110016
}

\begin{abstract}
Geothermal energy is a good alternative of fossil fuels and its usage is the most innovative and useful technology that contributes to environmental protection and provides substantial energy, long term cost savings and minimized maintenance. Geothermal energy can be extracted or injected to the earth through tunnels, where tunnels acts as a heat exchanger, in which absorber pipes are fitted, which are circulated with heat transfer liquid. In cities, tunnels provide access for rail, road and utilities. They can also be used as ground heat exchanger for GSHP (Ground Source Heat Pump) systems. Tunnels dug underground use geothermal power to bring our home temperature to earth temperature, i.e helps in heating and cooling. The concept for the thermal tunnel utilizes the temperature difference between the ground and inlet temperature, via compression (heating) or expansion (cooling), to generate building heating or cooling. The system is reversible and operated at best efficiency between seasons. Response of the tunnel as a element has to be recorded and studied. ABAQUS is finite element software (FEM) used for the analysis. Study deals with the simulation of geothermal tunnels using ABAQUS, involving heat transfer analysis and coupled thermo-mechanical analysis using a 3-D model. The model has been analysed for finding out thermal stresses, temperature and displacements on concrete lining, embedded pipes and the soil in which tunnel is being constructed. Results are generated in the form of various plots after running the analysis for a duration of 8 years.
\end{abstract}

Keywords: Geothermal tunnels, ABAQUS, FEM, GSHP, Coupled thermo-mechanical.

\section{INTRODUCTION}

Geothermal tunnels are not separately used for heating and cooling of the bulding, it's a concept in which tunnels already being provided for the structural purposes is supplied with an extra arrangement of loops of pipes, circulated with fluid, to transfer geothermal energy from earth to the building for its operational heating and cooling purposes. (Fig. 1)

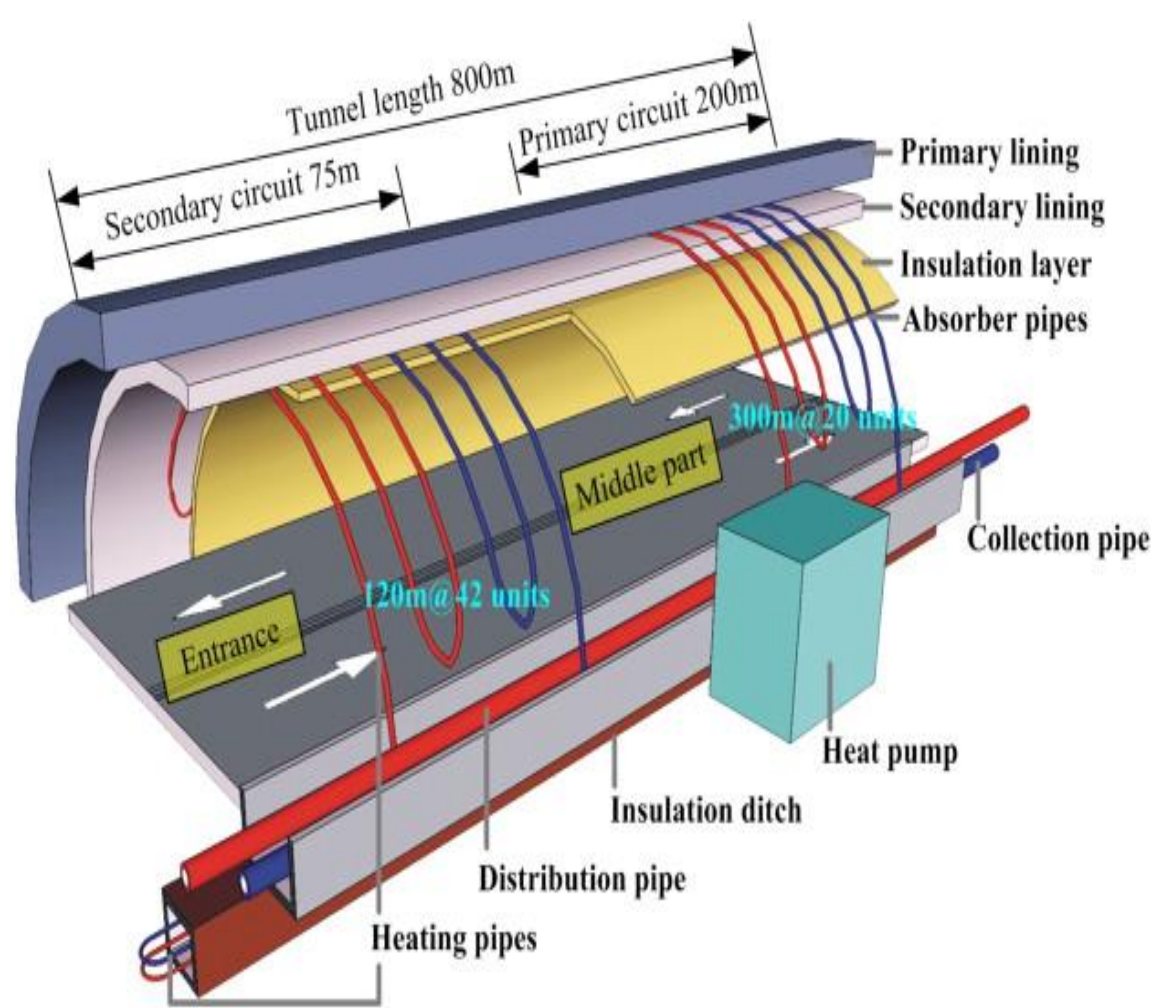

Fig -1: Schematic view of tunnel heating system using heat pump (Zhang Guozhu et al., 2012) 
Being acting like a heat exchanger, tunnels are subjected to additional thermal stresses which complicates their behavior and it needs to be studied. When tunnels are provided and used as heat exchanger also, they are acted upon by thermal loads. The response of the tunnel as a element has to be recorded and studied. Otherwise it may exceed the failure limits of the material. Therefore it is analysed by finite element method techniques (FEM).

These tunnels can be considered as cold and hot tunnels. The cold tunnels access heat from the surrounding ground. The hot tunnels itself acts as a heat source. The model analysed in this study is cold tunnel. (Fig.2)

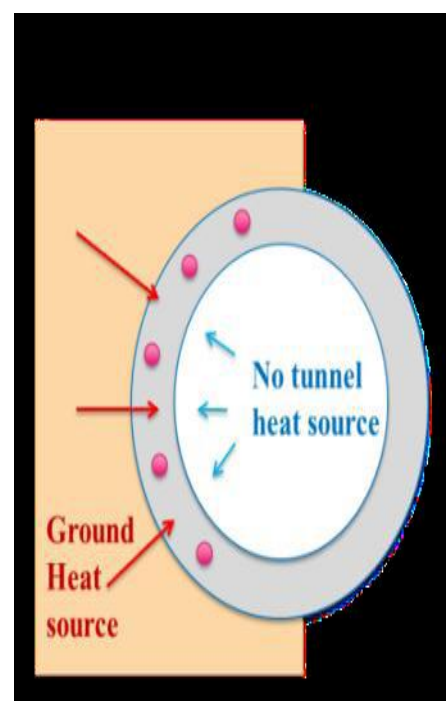

(a)

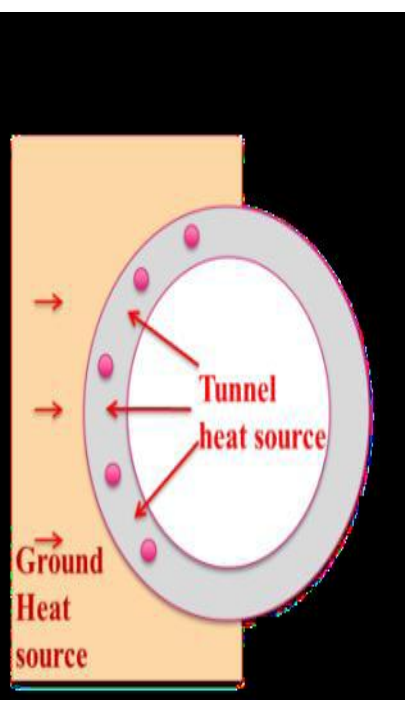

(b)
Fig -2: (a) cold tunnel (b) hot tunnel (Nicholson D. P. et al., 2013)

\subsection{Abaqus/CAE}

Abaqus/CAE, or "Complete Abaqus Environment is a software application used for both the modelling and analysis of mechanical components and assemblies and visualizing the finite element analysis result. Designed as a general purpose simulation tool, it can be used to study more than just problems, likewise it is used here to simulate problem of heat transfer.

\subsection{FEM Analysis}

The finite element method (FEM) is a numerical technique for finding approximate solutions to boundary value problems for differential equations. It uses variational methods (the calculus of variations) to minimize an error function and produce a stable solution. In this method, structure is being cut into several elements. Each element is analysed individually and then nodes of each element are reconnected to hold all the elements together and then overall behaviour of the structure is studied. It involves preprocessing, processing and post-processing of data.

\subsection{GSHP System}

The heat pump is a mechanical device that functions like a refrigerator. Its basic components include the compressor and expansion valve. The former compresses the refrigerant withing the pump to a gaseous state. Upon reaching the expansion valve, the gas undergoes a change of state from gaseous to liquid and the cycle repeats itself. Primary and secondary units will supply and receive the thermal energy contained within the pump allowing for the cycle to run. Reversible heat pumps are required for seasonal operation of the ground-source heat exchanger system as winter and summer cycles require different heating and cooling operations to take place. (Fig.3)

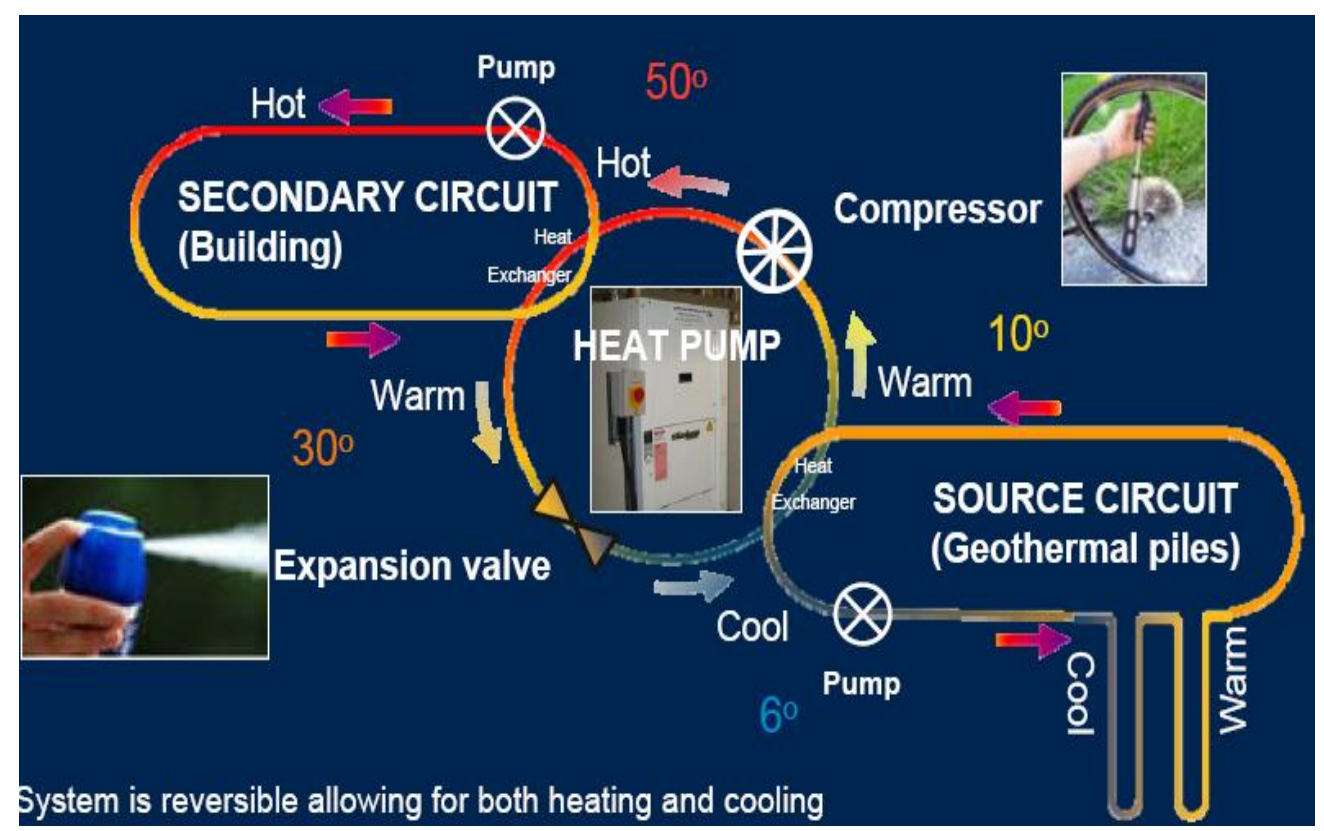

Fig -3: Working of ground source heat pump system 
Primary function of secondary unit is to utilize the extracted thermal energy for heating purposes during the winter and to receive unwanted heat from its surroundings in summer for transfer into the ground.

\subsection{Fully Coupled Thermo-mechanical Analysis}

Temperature changes cause axial and radial deformation which affects the contact. Contact affects temperature, and temperature distorts the parts, which affects the contact. The system is thus fully coupled. The problem is thus solved using fully coupled thermo-mechanical analysis capability in ABAQUS/Standard.

\section{PROBLEM STATEMENT AND 3-D ANALYSIS}

The thermal tunnel design is based on modeling the heat transfer from the tunnel air and the surrounding ground to the water filled pipes in the segments. The model has been caaliberated against periods with TES (thermal energy segments) heat extraction rates of $10 \mathrm{~W} / \mathrm{m}^{2}$ and $30 \mathrm{~W} / \mathrm{m}^{2}$. A generalized study is done for sandy soil. The soil's and concrete's behavior is modeled by using plasticity models in finite element software ABAQUS.

\subsection{Model Geometry}

A circular tunnel can be constructed by assembling different curved elements. Instead of analyzing the circular tunnel as a whole, the curved elements are analysed neglecting the curvature while forming the model.

The model of each element includes soil domain, concrete lining, and steel pipes. Lining and soil are modeled as a 3-D deformable solid of extrusion type and pipes are modeled as 3-D deformable shell of extrusion type. Lining part was further partitioned to separately define the surfaces which will be in contact with the pipes. Soil domain was extruded to accommodate the lining in which pipes are allowed to rest over the soil domain. To separate the behavior of lining and soil, contact conditions are defined between soil and lining, and pipe and lining. (Fig.4)

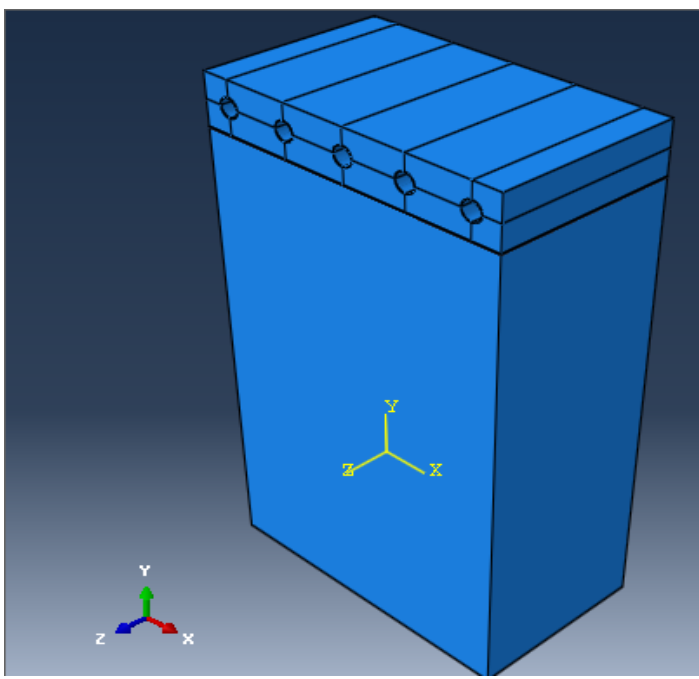

Fig -4: Assembled model

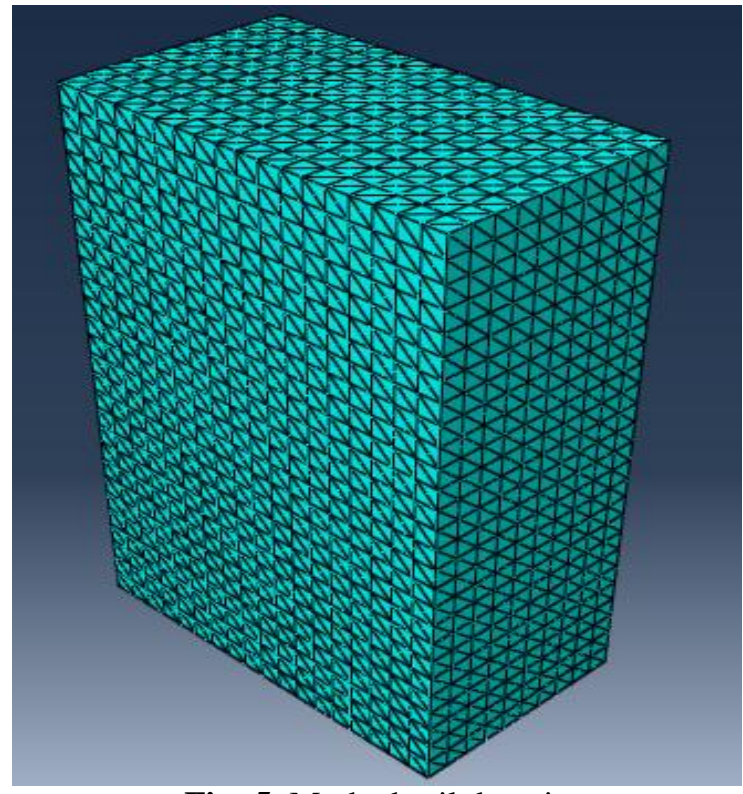

Fig -5: Meshed soil domain

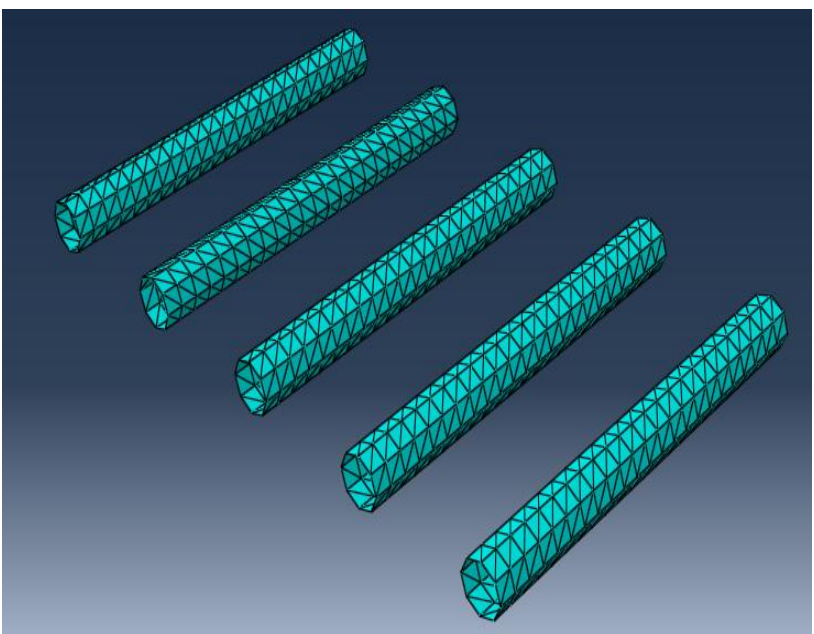

Fig -6: Meshed pipe part

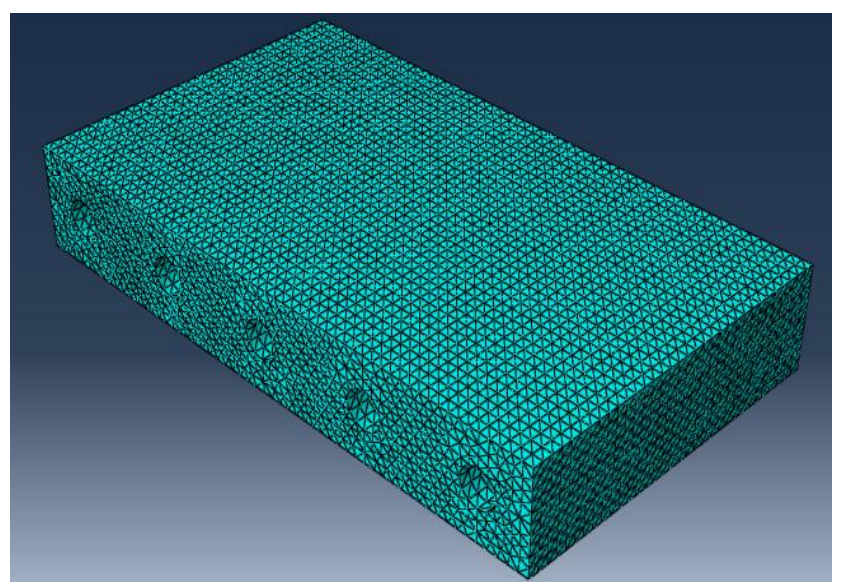

Fig -7: Meshed lining part

For discretization, meshing is being done. Considering 3-D 8-noded thermally coupled elements for soil and lining, and 3 -noded shell element have been considered for pipes. The elements have both displacement and temperature degrees of freedom. (Fig.5, Fig.6, Fig.7) 


\subsection{Material Properties}

The plastic behavior of soil was modeled using the MohrCoulomb constitutive plasticity model. Concrete damaged plasticity model was used to capture the plastic behavior of concrete. The soil properties also consisted of thermal properties governing its thermal behavior. The properties of soil like density $(\rho)$, modulus of elasticity (E), Poisson's ratio (v) are referred from book "Properties of Geotechnical Engineering ( $5^{\text {th }}$ Indian Edition)" by B.M. Das.

\subsection{Boundary and Loading Conditions}

Mechanical as well as temperature boundary conditions were applied. Bottom of soil domain being fixed, sides of the model given roller support and rest all faces were allowed to deform. Pumps that are being used to circulate water in the pipes are simulated by giving temperature boundary condition in the pipes in the sinusoidal form as shown (Fig.8) for extraction rates 30W and 10W applied in the pipes.

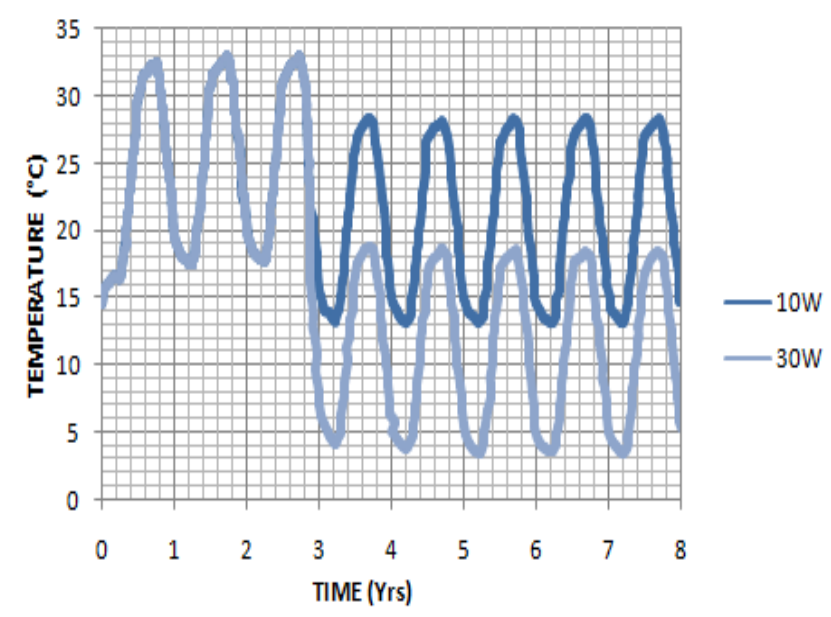

Fig -8: Temperature variation in pipes

Above Fig. 8 shows extraction of heat per $\mathrm{m}^{2}$ of tunnel is more when pipes are at lower average temperature than when they are at higher average temperature.

\section{ANALYSIS OF 3-D MODEL}

Transient state analysis is run by considering soil domain both as dense sand and loose sand as separate cases. Both the analysis are run for two different extraction rates separately i.e $30 \mathrm{~W} / \mathrm{m}^{2}$ and $10 \mathrm{~W} / \mathrm{m}^{2}$, analyzing tunnel as geothermal tunnel. Each case is analyzed with combined mechanical and thermal loads for heating and cooling, applied for 8 years.

\section{RESULTS AND DISCUSSIONS}

The model has been analyzed for finding out the thermal stresses, temperature, and displacements on concrete lining, embedded pipes, and the soil in which tunnel is being constructed. The results are being plotted in terms of stresses v/s time, displacement v/s time and temperature v/s time plots.

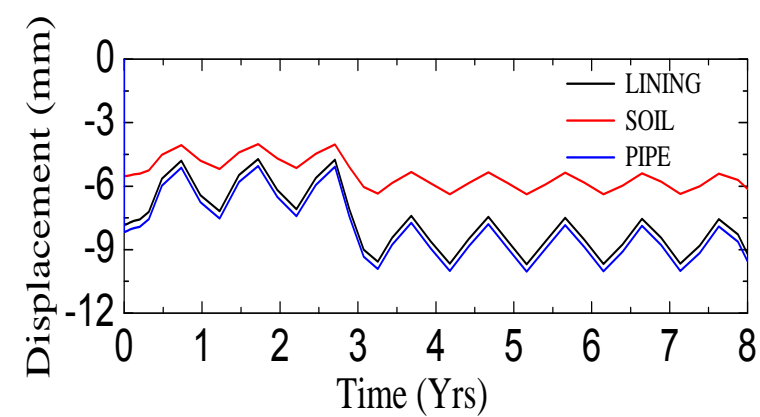

Fig -9:Displacement with time for $30 \mathrm{~W}$

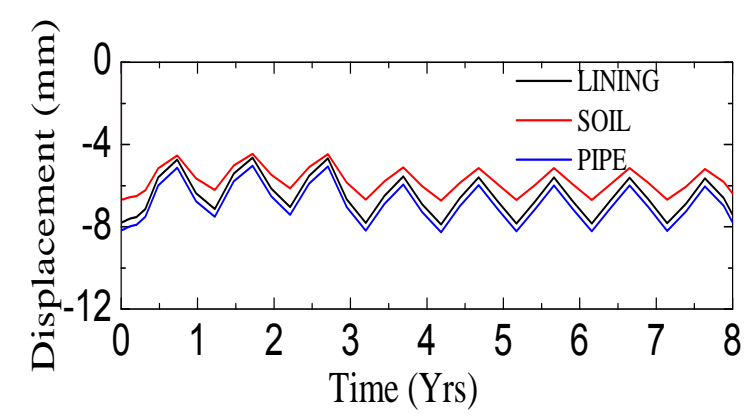

Fig -10:Displacement with time for $10 \mathrm{~W}$

Soil is seen to be displaced more than lining and pipes and settlement being in the downward direction. (Fig.9, Fig.10)

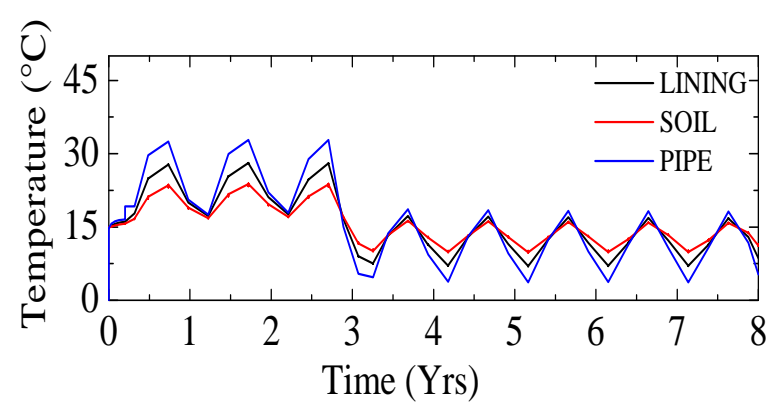

Fig -11:Temperature with time in for $30 \mathrm{~W}$

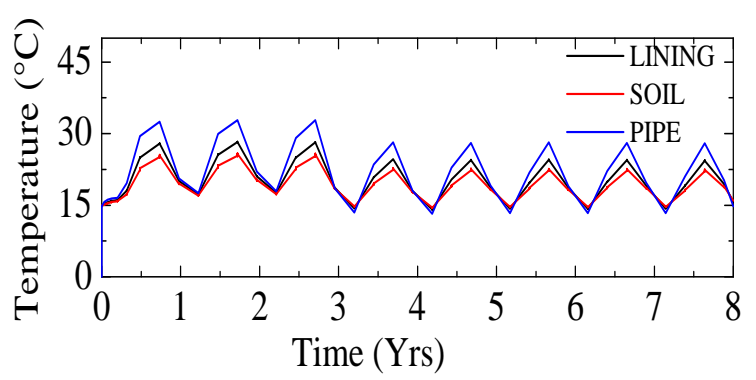

Fig -12:Temperature with time in for $10 \mathrm{~W}$

Range of temperature variation is more for more extraction rate. Specific heat of soil being higher than concrete than steel, shows lesser temperature variation compared to other two. (Fig.11, Fig.12) 


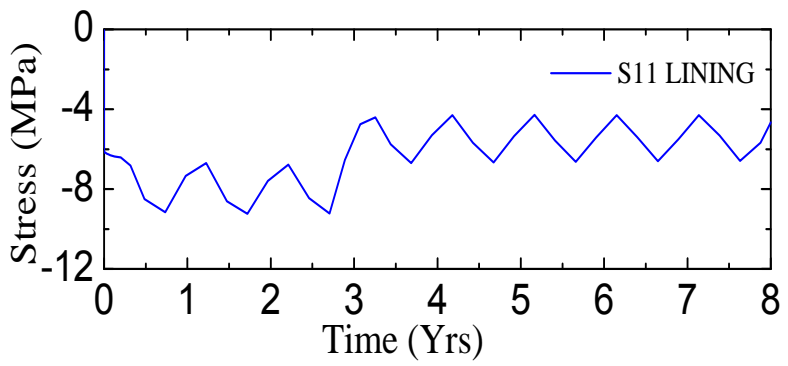

Fig -13: Stress in lining with time for $30 \mathrm{~W}$

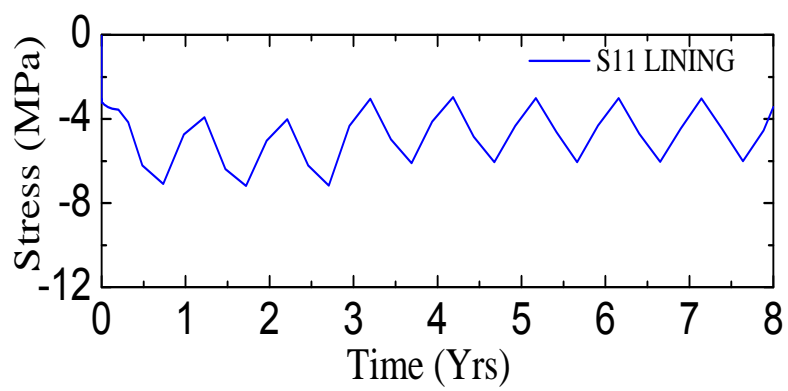

Fig -14: Stress in lining with time for $10 \mathrm{~W}$

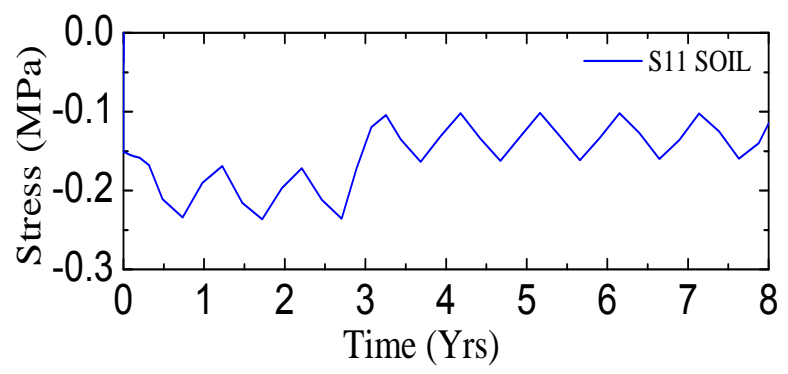

Fig -15: Stresses in soil with time for $30 \mathrm{~W}$

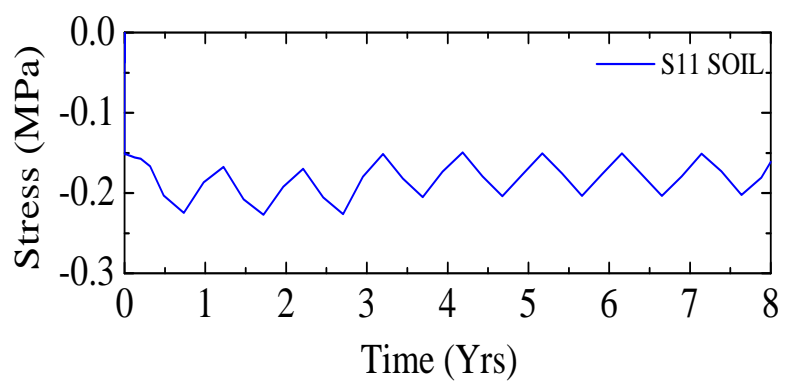

Fig -16: Stresses in soil with time for $10 \mathrm{~W}$

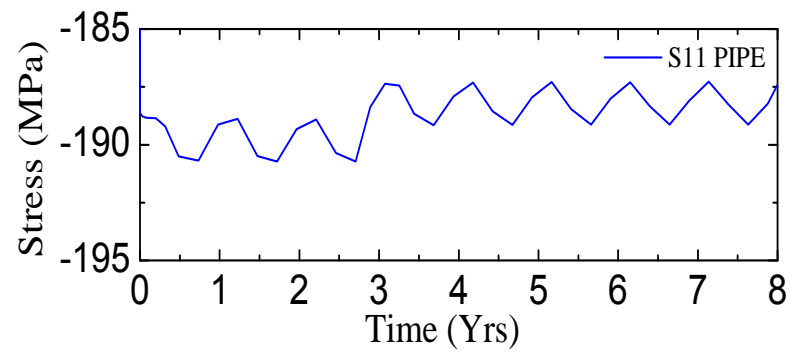

Fig -17: Stresses in pipe with time for $30 \mathrm{~W}$

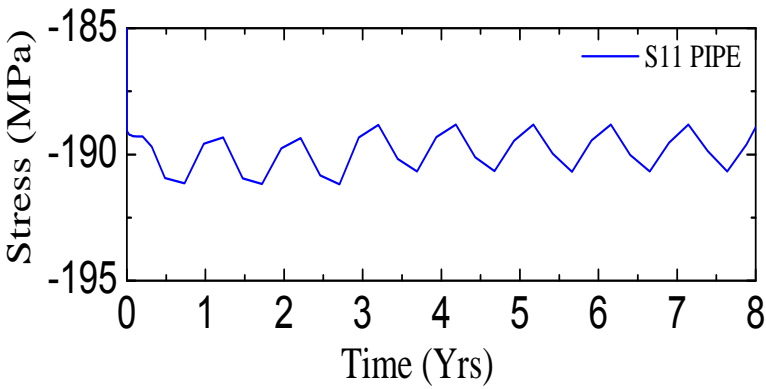

Fig -18: Stresses in pipe with time for $10 \mathrm{~W}$

Magnitude of stresses does not vary much with the extraction rates as can be seen from the plots for $30 \mathrm{~W}$ and $10 \mathrm{~W}$. But this can be clearly seen that stresses induced in pipes are very large compared to the stresses induced in lining and soil domain. Though nature of stresses in all three material is same, being compressive for all 8 years of analysis and showing sinusoidal behavior throughout. (Fig.13, Fig.14, Fig.15, Fig.16, Fig.17, Fig.18)

\section{SITE VISIT}

Neemrana is an ancient historical town in Alwar district of Rajasthan, India, situated at $122 \mathrm{Km}$ from Delhi on DelhiJaipur highway. Neemrana is the site of NIIT University which won the India Today award for the Greenest Campus.

Type of soil available in Rajasthan is mostly sandy. Project used in NIIT University is named as Earth Air-Tunnel and is a perfect application of this project. The system uses only $30 \%$ of the energy that a normal air conditioning system would use. In this system, fresh air is drawn through a long underground duct, laid $4 \mathrm{~m}$ below the ground called the earth air tunnel. Heat exchange with the underground duct cools down the air which is further treated for temperature, humidity and dust before it is brought into the building and supplied to every room. This air cools down the room and is exhausted through a chimney. The system works with $100 \%$ fresh air and maintains a healthy environment inside.

NIIT university is spread over 100 acres of land in Neemrana. Being situated in Rajasthan, its surrounding has very dry hot air with its temperature reaching to about $45^{\circ} \mathrm{C}$, which makes the survival hard for the dwellers. For the comfortable stay of students, university has provided each one of them with AC's in their rooms, though its hard to believe but it is not less than that. This is made possible by the use of renewable energy source i.e geothermal energy and construction of earth air tunnel.

Intake towers are constructed as shown in Fig.19, 5m deep and $12 \mathrm{~m}$ tall to collect dry hot air from the surroundings, fitted with various filters to purify air from dust particles. 10 such towers are being constructed. $5 \mathrm{~m}$ down the ground level, $120 \mathrm{~m}$ long tunnels are being constructed of diameter $1.2 \mathrm{~m}$ with sandy soil all around. 14 such tunnels are being constructed. Earth temperature which is found to be $30^{\circ} \mathrm{C}$ led to the fall of air temperature from $45^{\circ} \mathrm{C}$ to somewhere around $33^{\circ} \mathrm{C}$. This air is further taken to the air handling unit 
as shown in Fig.20, where fan is provided to suck the air, micron filters are provided to remove micro sized particles from the air and then it is passed through air washer pads as shown in Fig.21. These washer pads further drops air temperature to about $22^{\circ} \mathrm{C}$ and this cooled air is supplied in various rooms for perfect cooling as shown in Fig.22.

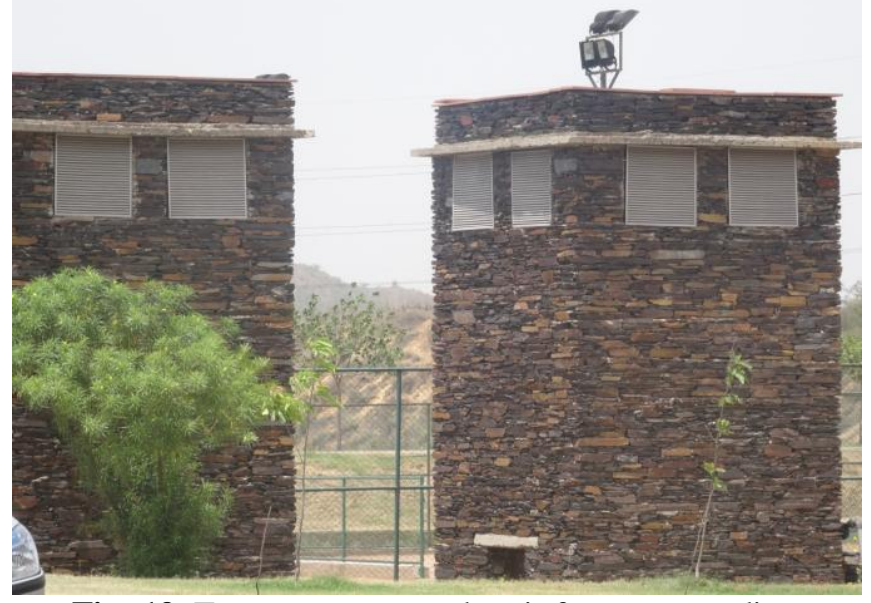

Fig -19: Towers to capture dry air from surrounding

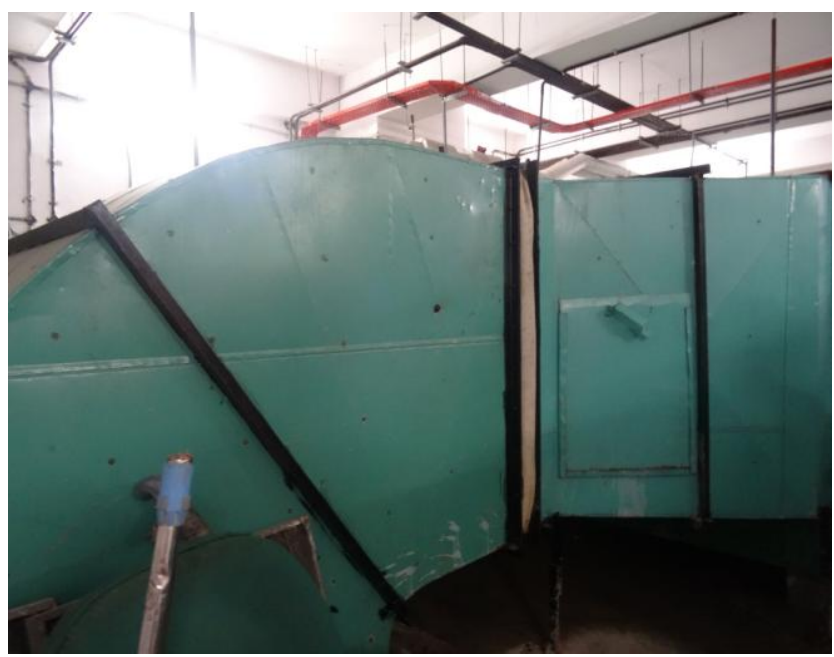

Fig -20: Air handling unit

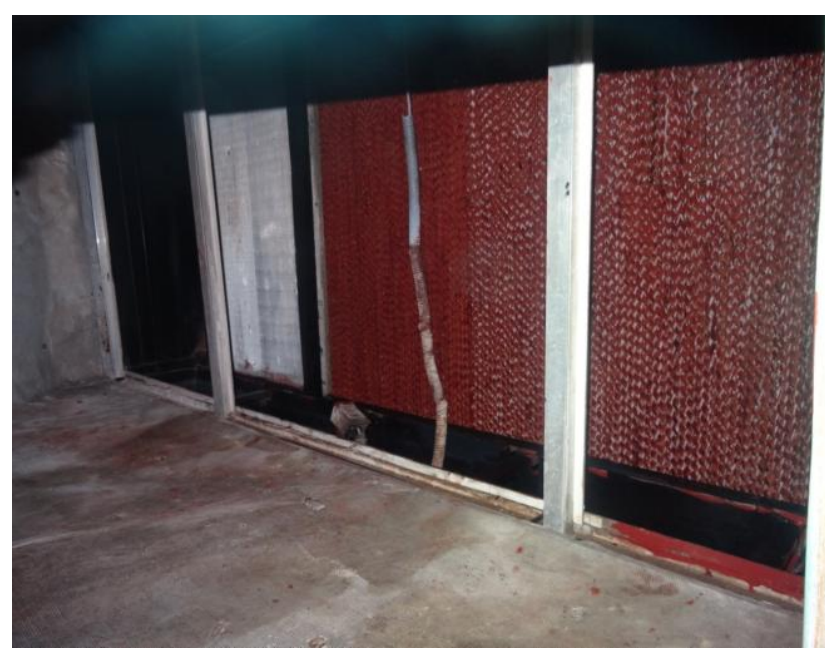

Fig -21: Air washer pads
Exhaust is provided through chimneys as shown in Fig.23, However at the time of rainfall when dry air becomes humid, normal washer pads don't prove to be that effective, for which chiller coils are being used. Conversely when in winters heating is required in place of cooling, boilers needs to be used but on application they are not found to be that effective.
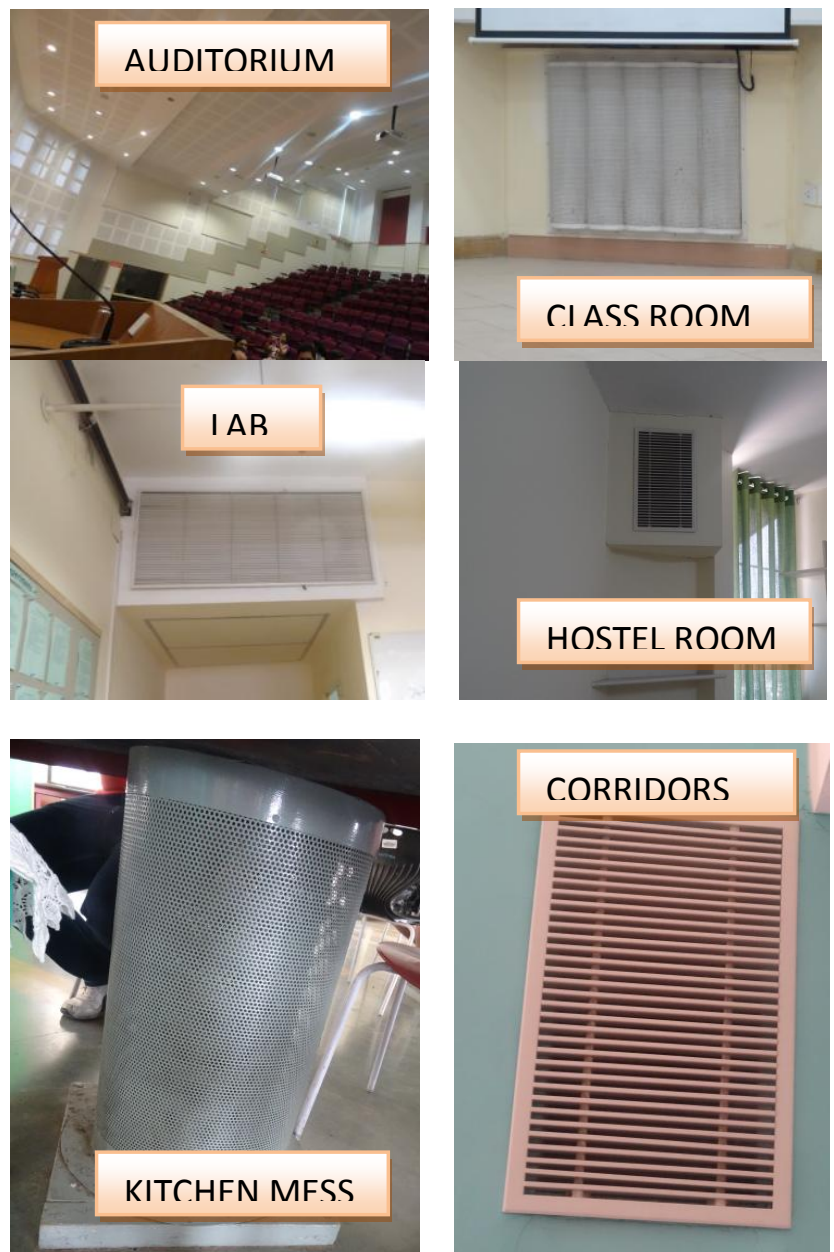

Fig -22: Supply in rooms

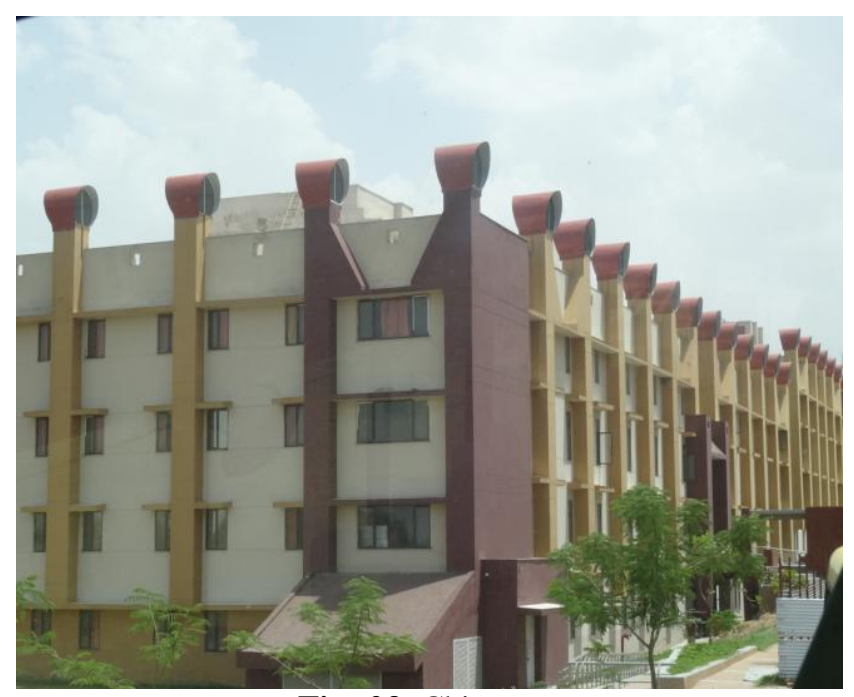

Fig -23: Chimneys 


\section{CONCLUSIONS}

The design is linked to hot tunnels where heat is extracted from the tunnel air and transferred to the surface for domestic hot water production and heating. The results for temperature, thermal stresses and displacements are produced after the transient state analysis is run successfully for 8 years.

The thermal tunnel design is based on modeling the heat transfer from the tunnel air and the surrounding ground to the water filled pipes in the segments. The ABAQUS numerical model is used to assess this transfer. The model has been calibrated against periods with TES heat extraction rates of $30 \mathrm{~W} / \mathrm{m}^{2}$ and $10 \mathrm{~W} / \mathrm{m}^{2}$ for sandy soil.

It is known that compressive strength of steel is 250-500 $\mathrm{MPa}$, that of concrete is $15-20 \mathrm{MPa}$ depending upon the grade of concrete and that of sand is 0.2 to $0.6 \mathrm{MPa}$. Thus from the results and plots obtained, it can be inferred that stresses induced due to temperature variation and the displacements caused in all three i.e lining, pipes and soil are within permissible limits and hence forth tunnels already constructed for transportation purpose can be put to be used as GSHP system for heat extraction from soil and supplying it in building on earth.

\section{ACKNOWLEDGEMENTS}

The authors would like to express their deep gratitude towards high authorities in NIIT University who allowed a campus visit to their university to understand the practical utility of this project work. They would also like to thank the members of Project Evaluation Committee and Geotechnical faculty of IIT Delhi, for their comments and valuable suggestions to improve the quality of this work.

\section{REFERENCES}

[1]. Nicholson, D. P., Chen, Q., Pillai, A., \& Chendorain, M. (2013). Developments in thermal pile and thermal tunnel linings for city scale GSHP systems. In Proceedings of the 38th Workshop on Geothermal Reservoir Engineering.

[2]. Rybach, L. (1995). "Thermal waters in deep alpine tunnels." Geothermics, 24(5), 631-637.

[3]. ZHANG, G., Xia, C. C., Ma, X. G., LI, P., \& WEI, Q. (2012). "Rock-soil thermal response test of tunnel heating system using heat pump in cold region." Chinese Journal of Rock Mechanics and Engineering, 31(1), 99-105.

[4]. Rybach, L., Wilhelm, J., \& Gorhan, H. (2003, September). "Geothermal use of tunnel waters-a Swiss specialty." In International Geothermal Conference, Reykjavík, Session (Vol. 5).

[5]. Lienau, P. J., \& Lund, J. W. (1974). "Multipurpose use of geothermal energy." (No. OIT-74-1Z). Oregon Institute of Technology, Klamath Falls, OR.

[6]. Hwang, S., Ooka, R., \& Nam, Y. (2010). "Evaluation of estimation method of ground properties for the ground source heat pump system." Renewable energy,35(9), 21232130 .

\section{BIOGRAPHIES}

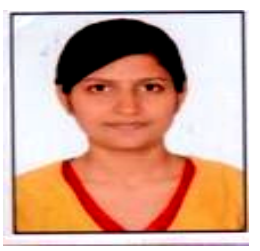

Aparna Kanth, is an Assistant Professor in Civil Engg. Dept. of Skyline Institute of Engg. and Tech., Greater Noida, U.P, India-201308

(email-aparnakanth.12@gmail.com), M.Tech is completed in Geotechnical Engg. from IIT Delhi,

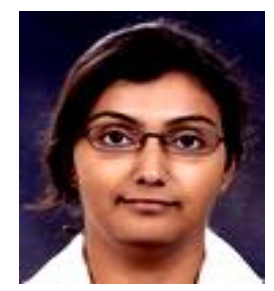

Dr.Tanusree Chakraborty is an Assistant Professor in Civil Engg. Dept. of IIT Delhi, Delhi, India-110016 (emailtanusree@civil.iitd.ac.in) Ph.D is completed from Purdue University, West Lafayette, USA. 